\title{
UNILATERAL OBLITERATION OF THE PULMONARY ARTERY IN EMPHYSEMA
}

\author{
BY \\ J. G. STEVENSON AND J. M. REID \\ From the Thoracic Unit, Mearnskirk Hospital
}

(RECEIVED FOR PUBLICATION OCTOBER 17, 1958)

The inexorable progression of exertional dyspnoea in patients afflicted by chronic bronchitis and emphysema constitutes a symptomatology accepted with resignation by chest physicians and surgeons alike. In general its treatment is largely symptomatic and entirely palliative. In some instances, however, the onward march of dyspnoea may be rapid, and when this increase in symptoms is superimposed on a long-standing background of chronic cough, sputum, and breathlessness, it is worth while to bear in mind that the emphysematous condition may be predominantly unilateral, and produce undue changes in the pulmonary vascular bed that culminate in obliteration of the ipsilateral pulmonary artery.

We feel it is valuable to describe the following case to illustrate the diagnostic facets which assist in the evaluation of this condition.

\section{CAse Report}

A man, aged 45 years, was referred to the Thoracic Unit at Mearnskirk Hospital on April 8, 1958, for investigation of progressive exertional dyspnoea. $\mathrm{He}$ gave a history of having had a chronic productive cough for over 20 years, but breathlessness, although present in a minor degree, had not been a prominent symptom. Over the past year dyspnoea on exercise had become increasingly more marked, and as a result a month before admission here he had been referred for assessment to the out-patient department of a neighbouring hospital. After clinical and radiological examination the physician noted the relative translucency of the right lung field (Fig. 1). $\mathrm{He}$ felt that an obliterative condition of the right pulmonary artery was in question, and that more specialized investigation was called for.

On examination the patient was found to be a small, slightly built man (height $152 \mathrm{~cm}$., weight $54 \mathrm{~kg}$.) with mild finger clubbing. There was no cyanosis or dyspnoea at rest. There was limited but even respiratory excursion, and the percussion note was resonant. The respiratory murmur was vesicular, and there were a few rhonchi at the right base. The blood pressure was $130 / 75 \mathrm{~mm}$. of mercury. The sputum was mucoid, and contained $\vec{\phi}_{\infty}$ no pathogenic bacteria, but a postero-anterior chest $\stackrel{\infty}{N}$ radiograph confirmed the deficient right-sided $\mathrm{O}$ vascular markings. The following estimations of lung function were performed. A vital capacity 3 reading of $1,500 \mathrm{ml}$. was obtained. The maximum voluntary ventilation (60 respirations per minute) was $\frac{\widehat{O}}{\partial}$ 30 litres per minute. The corresponding predicted values based on sex, age, weight, height, and surface $\mathcal{E}$ area were $3,420 \mathrm{ml}$. and 93 litres per minute. respectively. The forced expiratory volume $(1 \mathrm{sec}$. was $33 \%$ of the vital capacity (expected value $92 \%$ ). Intact ear oximetry gave an oxygen saturation level of $93 \%$ at rest. After moderate walking exercise the figure dropped to $89 \%$.

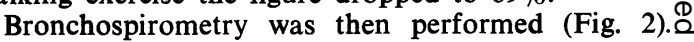
The right lung had a vital capacity of $450 \mathrm{ml}$. (33\% $\overrightarrow{\vec{O}}$ of the total), and a tidal air reading of $100 \mathrm{ml}$. (27\% $\frac{3}{3}$ of the total). Its oxygen uptake, however, was nil.

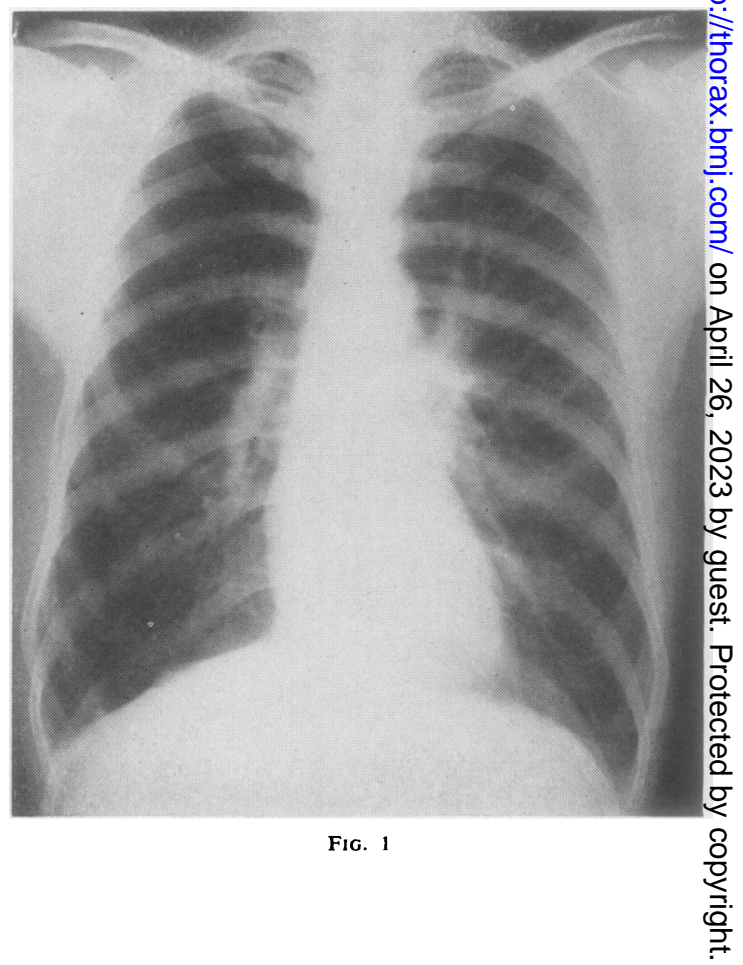




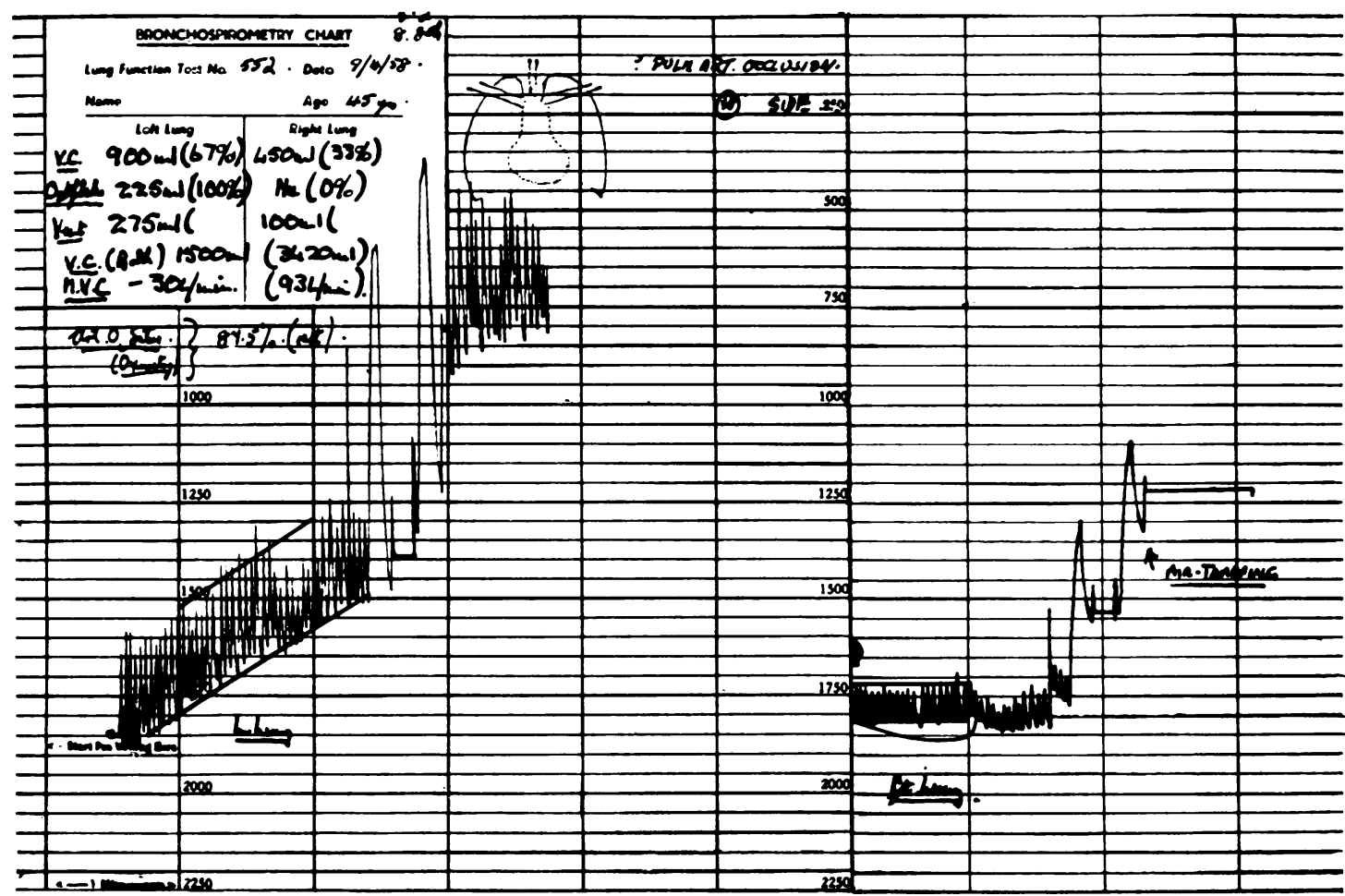

Fig. 2

The corresponding figures for the left lung were $900 \mathrm{ml}$. (67\%), $275 \mathrm{ml}$. (73\%), and $225 \mathrm{ml}$. (100\%), respectively. An electrocardiograph showed right axis deviation but no evidence of right ventricular strain.

Fluoroscopy again demonstrated the absence of vascular markings in the right lung field. It showed,

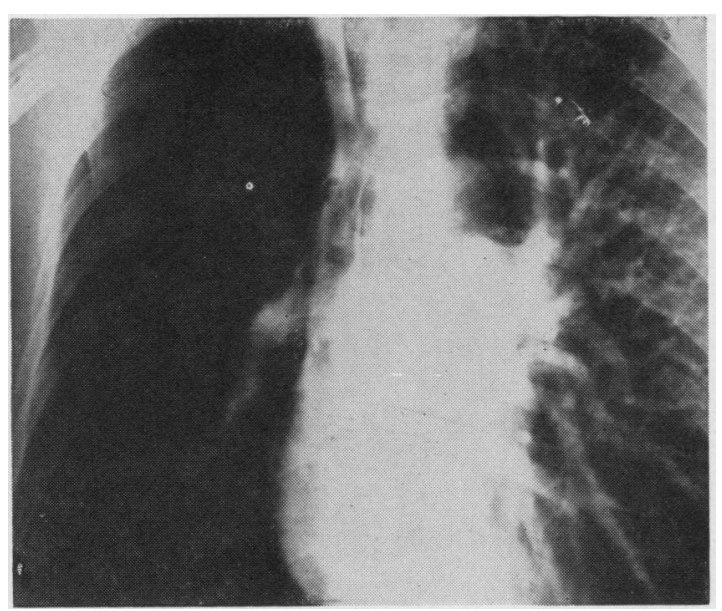

Fig. 3 too, quite marked obstructive emphysematous changes, with defective expulsion of air from the right side and consequent ballooning of the right lung on expiration. Bronchography revealed no significant bronchiectasis but demonstrated the absence of terminal bronchiolar and alveolar filling.

Angiocardiography was performed under basal sedation on April 21 (Fig. 3). This showed adequate filling of the main pulmonary artery, a complete arteriogram of the left lung, and a total absence of distal vascular markings on the right side. The right pulmonary artery tapered to complete obliteration at the level of its intermediate subdivisions.

\section{Discussion}

Despite the absence of previous descriptions of this condition, we feel it may not be so uncommon as this would suggest. The progression of symptoms in a chronic bronchitic patient is slow; and the depletion of respiratory reserve takes many years to develop. When obliteration of the pulmonary circulation is superimposed marked acceleration of symptoms results. The patient may state with certainty that dyspnoea his increased seriously over a short period of months-perhaps to a degree that seriously threatens his working 
capacity. Radiological examination at this stage can demonstrate the reduced vascular markings and increased translucency of one or other lung field. Fluoroscopy confirms this, and in addition may show obstructive emphysema.

The diagnosis is firmly made by two main tests. First, differential assessment of lung function by bronchospirometry shows that the affected lung, while possessing a normal, or perhaps slightly subnormal, vital capacity and tidal air, absorbs no oxygen from the spirometer at all. Angiocardiography confirms the position pictorially as in Fig. 3.

Certain other conditions may cause unilateral obliteration or occlusion of the pulmonary artery. Smart and Pattinson (1956) described a case of congenital absence of the pulmonary artery, utilizing both bronchospirometry and angiocardiography to establish the diagnosis. Bronchial carcinoma may lead to occlusion of the pulmonary artery by direct implication (Stevenson and Reid, 1957). It may also be accompanied by obstructive emphysema. In our case the absence of any radiological evidence of bronchial carcinoma, together with complete filling of the bronchial tree at bronchography, excluded the possibility of any underlying neoplastic process.

We feel that in this clinical entity, where it can be demonstrated that the affected lung is impeding the respiratory function of its fellow, as manifested by air-trapping and mediastinal shift, and provided the other lung is capable of supporting life alone, surgical extirpation of the offending lung should be a consideration. The patient we have described has been considered in this light, but operation has been postponed meantime. His symptoms are not extreme and he finds it easy to continue his sedentary duties as a foreman. He remains under out-patient survey and any progression of dyspnoea can be measured and if necessary treated surgically.

\section{Summary and CONCLUSIONS}

A case of unilateral obliteration of the pulmonary artery occurring in a patient with emphysema is described. Awareness of the possibility of this condition in a patient with a history of recurrent bronchitis and recent progressive dyspnoea, together with increased translucency of one lung radiologically, should lead to further investigation by lung function tests and angiocardiography.

The role of surgery in the treatment of this entity is mentioned.

The authors wish to thank Dr. Mitchell, Glasgow Royal Infirmary, for referring the case for investigation, and Mr. R. S. Barclay, Thoracic Surgeon, Mearnskirk Hospital, under whose care the patient was admitted.

REFERENCES

Smart, J., and Pattinson, J. N. (1956). Brit. med. J., 1, 491. Stevenson, J. G., and Reid, J. M. (1957). Thorax, 12, 300. 